\title{
Tuning Solid-State Photoluminescence Frequencies and Efficiencies of Oligomers Containing One Central Thiophene-S,S-dioxide Unit
}

\author{
Giovanna Barbarella, ${ }^{*},{ }^{\dagger}$ Laura Favaretto, ${ }^{\dagger}$ Giovanna Sotgiu,${ }^{\dagger}$ Massimo Zambianchi, ${ }^{\dagger}$ \\ Alessandro Bongini, \\ Giuseppe Gigli," and Roberto Cingolani"
}

\begin{abstract}
Contribution from the Consiglio Nazionale Ricerche, I.Co.C.E.A, Via Gobetti 101, 40129 Bologna, Italy, Dipartimento di Chimica G. Ciamician, Universita', Via Selmi 2, 40126 Bologna, Italy, Istituto di Scienze Chimiche, Universita', Via San Donato 15, 40127 Bologna, Italy, and Istituto Nazionale di Fisica della Materia, Dipartimento Ingegneria Innovazione, Università di Lecce, Via Arnesano, 73100 Lecce, Italy
\end{abstract}

Received June 7, 2000

\begin{abstract}
We have synthesized thienylene- and phenylene-based oligomers displaying solid-state photoluminescence efficiencies up to $70 \%$ and photoluminescence frequencies which cover the entire visible range. All compounds contain one central nonaromatic thienyl-1,1-dioxide moiety in the main chain. The tuning of the light-emission frequency was achieved by progressively varying the degree of $\pi-\pi$ electron delocalization between the nonaromatic moiety and the $\alpha$-linked aromatic rings. All compounds displayed greater electron affinities than thienylene or phenylene oligomers of comparable lengths, as deduced from the reduction potentials measured by cyclic voltammetry.
\end{abstract}

\section{Introduction}

Organic molecules with high photoluminescence efficiencies are increasingly in demand for application in many research fields from fabricating electroluminescent devices for flat-panel display technology to probing biologically important molecules in fluorescent immunoassays or single-molecule spectroscopy. ${ }^{1,2}$ Of course, different applications require different characteristics. For example, electroluminescent devices require materialseither small molecules ${ }^{3}$ or polymers ${ }^{4}$-that are not only fluorescent but also electroactive and with high electron affinities. ${ }^{1}$ On the other hand, applications in medicine, biology, pharmacology, etc. require small fluorescent molecules that can be covalently and site-specifically attached to biomolecules ${ }^{2}$ so that

\footnotetext{
Consiglio Nazionale Ricerche, I.Co.C.E.A.

$\doteqdot$ Dipartimento di Chimica G. Ciamician, Universita', Via Selmi 2.

§ Istituto di Scienze Chimiche, Universita', Via San Donato 15.

"Università di Lecce.
}

(1) (a) Tang, C. W.; VanSlyke, S. A. Appl. Phys. Lett. 1987, 51, 913. (b) Burroughes, J. H.; Bradley, D. D. C.; Brown, A. R.; Marks, R. N.; Mackay, K.; Friend, R. H.; Burn, P. L.; Holmes, A. B. Nature 1990, 347, 539. (c) Berggren, M.; Inganäs, O.; Gustafsson, G.; Rasmusson, J.; Andersson, M. R.; Hjertberg, T.; Wennerström, O. Nature 1994, 372, 444. (d) Andersson, M. R.; Berggren, M.; Inganäs, O.; Gustafsson, G.; Gustafsson-Carlberg, J. C.; Selse, D.; Hjertberg, T.; Wennerström, O. Macromolecules 1995, 28, 7525. (e) Sheats, J. R.; Antoniadis, H.; Hueschen, M.; Leonard, W.; Miller, J.; Moon, R.; Roitman, D.; Stocking, A. Science 1996, 273, 884. (f) Cao, Y.; Parker, I. D.; Yu, G.; Zhang, C.; Heeger, A. J. Nature 1999, 397, 414. (g) Leising, G.; Tasch, S.; Graupner, W. In Handbook of Conductive Polymers; Skotheim, T., Elsenbaumer, R. L.; Reynolds, J. R., Eds.; Marcel Dekker: New York, 1998; pp 847-880. (h) Deshpande, R. S.; Bulovic, V.; Forrest, S. R. Appl. Phys. Lett. 1999, 75, 888. (i) O’Brien, D. F.; Baldo, M. A.; Thompson, M. E.; Forrest, S. R. Appl. Phys. Lett. 1999, 74, 442. (j) Sheats, J. R.; Chang, Y. L.; Roitman, D. B.; Stocking, A. Acc. Chem. Res. 1999, 32, 193.

(2) (a) Bruchez, M. P., Jr., Moronne, M.; Gin, P.; Weiss, S.; Alivisatos, A. P. Science 1998, 281, 2013. (b) Weiss, S. Science 1999, 283, 1676.

(3) Burrows, P. E.; Bulovic, V.; Gu, G.; Kozlov, V.; Forrest, S. R.; Thompson, M. E. Thin Solid Films 1998, 331, 101.

(4) (a)Kraft, A.; Grimsdale, A. G.; Holmes, A. B. Angew. Chem., Int. Ed. 1998, 37, 402. (b) Pei, J.; Yu, W. L.; Huang, W.; Heeger, A. J. Macromolecules 2000, 33, 2462. photoluminescence variations can report on biomolecule function. In these fields, the development of new fluorescent probes with photophysical properties better than those currently available is needed.

Thiophene-based oligomers - which have well-defined structures and monodispersed chain lengths ${ }^{5}$-are easily modified by the introduction of a variety of functional groups into the aromatic backbone and through thienyl sulfur functionalization. ${ }^{6 a, 7}$ They are chemically very stable with good electrical characteristics $^{8}$ and are also fluorescent molecules. Conventional thiophene oligomers have low photoluminescence efficiencies in the solid state ${ }^{9}$ but high photoluminescence efficiencies in solution. ${ }^{10}$ Studies in solution however have so far been limited by solubility problems, in particular for the longer compounds.

We have recently reported that the insertion of one thienyl$S, S$-dioxide moiety into the aromatic backbone makes thiophene oligomers attractive for LED applications. ${ }^{6 \mathrm{~d}, \mathrm{e}} \mathrm{We}$ have shown

(5) Müllen, K.; Wegner, G., Eds. Electronic Materials: The Oligomer Approach; Wiley-VCH: New York, 1998.

(6) (a) Barbarella, G.; Favaretto, L.; Sotgiu, G.; Zambianchi, M.; Antolini, L.; Pudova, O.; Bongini, A. J. Org. Chem. 1998, 63, 5497. (b) Barbarella, G.; Favaretto, L.; Zambianchi, M.; Pudova, O.; Arbizzani, C.; Bongini, A.; Mastragostino, M. Adv. Mater. 1998, 10, 551. (c) Barbarella, G.; Favaretto, L.; Sotgiu, G.; Zambianchi, M.; Arbizzani, C.; Bongini, A.; Mastragostino, M. Chem. Mater. 1999, 11, 2533. (d) Barbarella, G.; Favaretto, L.; Sotgiu, G.; Zambianchi, M.; Fattori, V.; Cocchi, M.; Cacialli, F.; Gigli, G.; Cingolani, R. Adv. Mater. 1999, 11, 1375. (e) Gigli, G.; Barbarella, G.; Favaretto, L.; Cacialli, F.; Cingolani, R. Appl. Phys. Lett. 1999, 75, 439. (f) Barbarella, G.; Zambianchi, M.; Bongini, A.; Antolini, L. Adv. Mater. 1993, 5, 834. (g) Barbarella, G.; Pudova, O.; Arbizzani, C.; Mastragostino, M.; Bongini, A. J. Org. Chem. 1998, 63, 1742.

(7) Jiang, B.; Tilley, T. D. J. Am. Chem. Soc. 1999, 121, 9744.

(8) (a) Garnier, F. Acc. Chem. Res. 1999, 32, 209. (b) Katz, H. E.; Laquindanum, J. G.; Lovinger, A. J. Chem. Mater. 1998, 10, 633.

(9) Ziegler, C. In Handbook of Organic Conductive Molecules and Polymers; Nalwa, H. S., Ed.; John Wiley \& Sons: Chichester, 1997; Vol 3 , pp $678-737$.

(10) (a) Kanemitsu, Y.; Suzuki, K.; Masumoto, Y.; Tomiuchi, Y. Shiraishi, Y.; Kuroda, M. Phys. Rev. B 1994, 50, 2301-2305. (b) Chosrovian, H.; Rentsch, S.; Grebner, D.; Dahm, U.; Birckner, E. Synth. Met. 1993, 60, 23. 
Table 1. Molecular Structure, Maximum Absorption Wavelengths in Solution $\left(\lambda_{\mathrm{Max}}, \mathrm{nm}\right)^{a}$ and in the Solid State $\left(\lambda_{\mathrm{A}}, \mathrm{nm}\right)^{b}$ and Solid-State Photoluminescence Frequencies $\left(\lambda_{\mathrm{PL}}, \mathrm{nm}\right)$ and Efficiencies $^{b}(\eta, \%)$ of Oligomers 1-15 and Solid-State Photoluminescence Frequencies of Heptamer 16 and Polymers P3, P5

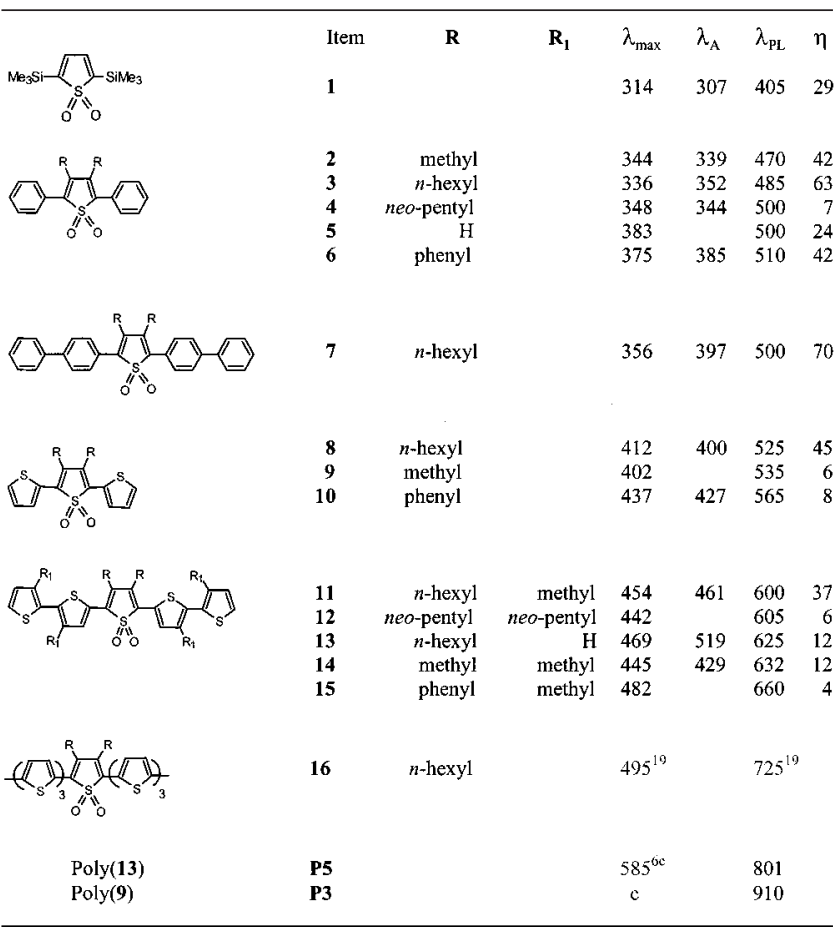

${ }^{a}$ In chloroform. ${ }^{b}$ Microcrystalline powders. Absolute photoluminescence efficiencies were measured using an integrating sphere (see the Experimental Section). ${ }^{c}$ Insoluble material.

that a pentamer containing one of these units under UV excitation emitted light with $37 \%$ photoluminescence efficiency in the solid state and that, thanks to the increase in electron affinity also caused by the modified thienyl unity, ${ }^{6 b}$ a LED fabricated with this material displayed high electroluminescence efficiency. ${ }^{6 e}$

Phenylene oligomers display high solid-state photoluminescence efficiencies. Hexa( $p$-phenylene), which is the most studied derivative of this class of compounds, displays $30 \%$ solid-state photoluminescence efficiency. ${ }^{1 \mathrm{~g}}$ Several high-performance devices based on poly ( $p$-phenylenes) have been described and are reviewed in ref $1 \mathrm{~g}$.

In this contribution we show that the insertion of one central thiophene-S,S-dioxide moiety into the backbone of thienylene and phenylene oligomers brings about a large increase in the solid-state photoluminescence efficiency accompanied by enhanced electron affinity, deduced from electrochemical reduction potentials measured by cyclic voltammetry.

\section{Results}

(I) Photoluminescence Properties. Table 1 shows the molecular structure and the photoluminescence frequencies and efficiencies of the microcrystalline powders of oligothiophene$S, S$-dioxides 1-15 under UV excitation $\left(\lambda_{\mathrm{exc}}=363 \mathrm{~nm}\right)$ together with the maximum wavelength absorptions of the same compounds in chloroform and in the solid state. Photoluminescence efficiencies similar to those reported in the table were obtained with cast films of the same compounds. For comparison, Table 1 also shows the photoluminescence frequency under excitation at $363 \mathrm{~nm}$ of heptamer $\mathbf{1 6}$ and the polymers obtained by oxidative polymerization of oligomers 9 and $\mathbf{1 3},{ }^{6 \mathrm{c}}$ named $\mathbf{P 3}$ and $\mathbf{P 5}$, respectively.

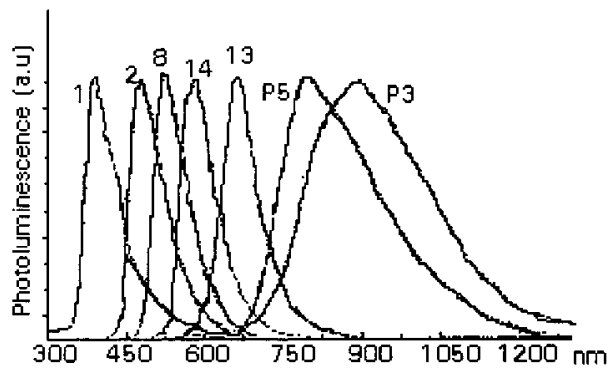

Figure 1. Normalized photoluminescence spectra obtained from the microcrystalline powders of selected oligomers and polymers containing one central thiophene-S,S-dioxide moiety. The numbers correspond to the structures reported in Table 1.

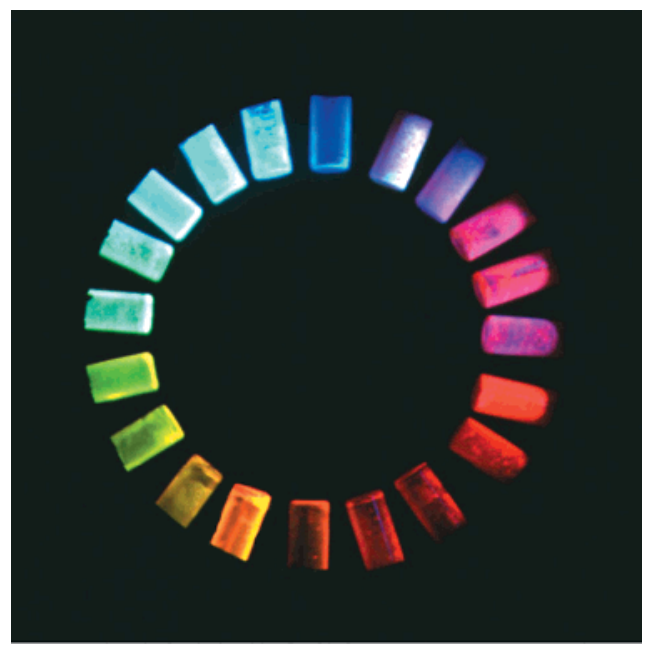

Figure 2. Cast films (from chloroform) of oligomers 1-15 under UV excitation $\left(\lambda_{\mathrm{exc}}=363 \mathrm{~nm}\right)$.

Figure 1 shows the normalized photoluminescence spectra of a few selected oligo- and poly(thiophene- $S, S$-dioxides), spanning from blue to near-IR

Figure 2 shows the photoluminescence emission of cast films (from chloroform) of oligothiophene-S,S-dioxides 1-15 under UV excitation at $363 \mathrm{~nm}$. Five of the films (the first five counting counterclockwise, starting after the blue film) which emit white and magenta light are relative to binary blends of oligomers. The coordinates of compounds $\mathbf{1 - 1 5}$ according to the formalism of the Commission Internationale de L' Eclairage $(\mathrm{CIE})^{11}$ are reported in a separate paper discussing the photoluminescence frequencies and efficiencies of binary blends as a function of the energy difference of the components. ${ }^{12}$

Table 1 and Figure 2 show that by changing the fragments attached to the central thienyl- $S, S$-dioxide moiety, a great variety of shades in the blue, green-yellow, orange, and red regions can be obtained. In all color ranges high solid-state photoluminescence efficiencies are attained. The compounds having the highest solid-state photoluminescence efficiencies are $\mathbf{2}-\mathbf{3}$, $5-7$, in which the oxygenated unit is $\alpha$-linked to phenyl groups, and $\mathbf{8}$ and $\mathbf{1 1}$ in which it is $\alpha$-linked to thienyl rings. For all compounds the emission wavelength undergoes a bathochromic shift with respect to the absorption wavelength, and Stokes shifts in the range $0.9-1.3 \mathrm{eV}$ are found for all compounds.

The maximum wavelength absorption values of $\mathbf{1 - 1 5}$ in solution as well as in the solid state, $\lambda_{\max }$ and $\lambda_{\mathrm{A}}$, depend on the oligomer length and on the degree of $\pi-\pi$ overlap between

(11) CIE Rancourt, J. D. Optical Thin Films User Handbook. SPIE Washington, DC, 1996.

(12) Anni, M.; Gigli, G.; Paladini, V.; Cingolani, R.; Barbarella, G.; Favaretto, L.; Sotgiu, G.; Zambianchi, M. Appl. Phys. Lett. 2000, 77, 2458 
Scheme 1. Molecular Structure $(\mathrm{Hex}=n$-hexyl; tBut $=$ tert-butyl) of Oligothiophene-S,S-dioxides that Are Not Fluorescent in the Solid State ${ }^{a}$

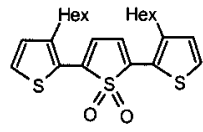

17

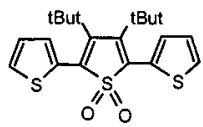

19

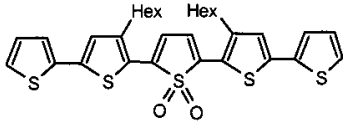

18

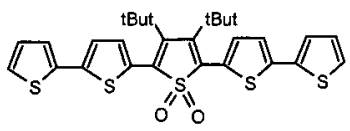

20
${ }^{a}$ Compounds 17-18 are fluorescent in solution while 19-20 are not.
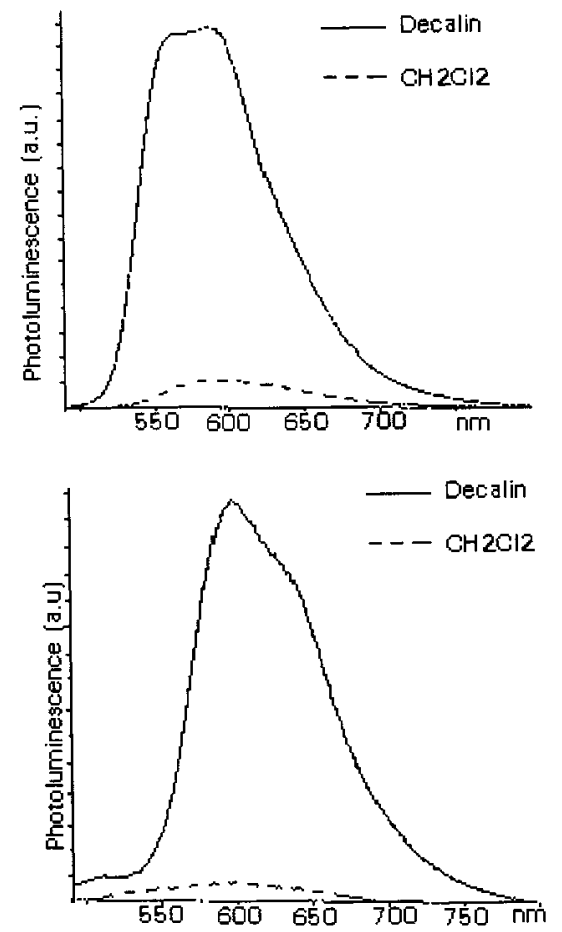

Figure 3. Photoluminescence spectra of pentamers 18 (bottom) and 13 (top) $10^{-5} \mathrm{M}$ in methylene chloride and Decalin.

the inner oxygenated unit and the $\alpha$-linked aromatic rings. When phenyls replace thienyl groups, the overlap is decreased (see below), and the photoluminescence frequency is smaller. Compare, for example, trimers 2-6 with trimers 8-10 or pentamer 7 with pentamers 11-15. In "all-thienyl" compounds, the absorption and emission wavelengths depend on the degree of backbone distortions induced by the $\beta$-substituents.

The photoluminescence frequencies of $\mathbf{P 5}$ and P3, 801 and $910 \mathrm{~nm}$, respectively, as well as those of heptamer 16, $725 \mathrm{~nm}$, are in the near-IR The photoluminescence spectra of $\mathbf{P 3}$ and P5 are very broad with light emission tails up to more than 1 $\mu \mathrm{m}$. The photoluminescence efficiencies of the microcrystalline powders of these polymers and of heptamer 16 were of only a few percent $(2-3 \%)$.

The absorption spectra of oligomers 17-20 (see Scheme 1) are similar to those of all the other compounds of Table 1 and with $\lambda_{\max }$ values of the magnitude expected for these kinds of compounds, but they do not display solid-state photoluminescence under UV excitation. However, $\mathbf{1 7}$ and $\mathbf{1 8}$ are photoluminescent in solution in the visible, whereas 19-20 are not.

Figure 3 shows the photoluminescence spectra of pentamer $1810^{-5} \mathrm{M}$ in methylene chloride and Decalin (bottom) and,
Table 2. Oxidation $\left(E_{\mathrm{p}, \mathrm{a}}\right)$ and Reduction $\left(E_{\mathrm{p}, \mathrm{c}}\right)$ Peak Potentials ${ }^{a}$ of Compounds 3, 6-8, 10, 11, 13, 18, and of Unsubstituted Oligothiophenes and Oligophenylenes of Comparable Size

\begin{tabular}{cccclccr}
\hline compound & $E_{\mathrm{p}, \mathrm{a}}$ & $E_{\mathrm{p}, \mathrm{c}}$ & $\Delta E^{\mathrm{b}}$ & \multicolumn{1}{c}{ compound } & $E_{\mathrm{p}, \mathrm{a}}$ & $E_{\mathrm{p}, \mathrm{c}}$ & $\Delta E^{\mathrm{b}}$ \\
\hline $\mathbf{3}$ & 1.85 & -1.57 & 3.42 & terphenylene $^{c}$ & 1.60 & -2.40 & 4.00 \\
$\mathbf{6}$ & 1.88 & -1.30 & 3.18 & quaterphenylene $^{c}$ & 1.47 & -2.28 & 3.75 \\
$\mathbf{7}$ & 1.73 & -1.41 & 3.14 & hexaphenylene $^{c}$ & 1.34 & -2.15 & 3.49 \\
$\mathbf{8}^{\text {7c }}$ & 1.59 & -1.35 & 2.94 & terthiophene $^{c}$ & 0.95 & -2.07 & 3.02 \\
$\mathbf{1 0}^{\mathbf{1 0}}$ & 1.43 & -1.16 & 2.59 & quaterthiophene $^{c}$ & 0.80 & -1.91 & 2.71 \\
$\mathbf{1 3}^{\text {7c }}$ & 1.10 & -1.34 & 2.44 & sexithiophene $^{c}$ & 0.65 & -1.78 & 2.43 \\
$\mathbf{1 8}^{1.33}$ & -1.24 & 2.57 & & & & \\
& 1.07 & -1.14 & 2.21 & & & &
\end{tabular}

${ }^{a} \mathrm{~V}$ vs saturated calomel electrode, by cyclic voltammetry. ${ }^{b}$ Electrochemical gap, $\Delta E=E_{\mathrm{p}, \mathrm{a}}-E_{\mathrm{p}, \mathrm{c} .}{ }^{c}$ From ref 13.

for comparison, also those of the regioisomeric pentamer $\mathbf{1 3}$ (top) which displays photoluminescence both in the solid state (see Table 1) and in solution. Contrary to that in the solid state, the behavior of $\mathbf{1 8}$ in solution is similar to that of $\mathbf{1 3}$, as the photoluminescence spectra of both compounds display very low intensity in methylene chloride and much higher intensity in Decalin. Moreover, when the Decalin solution of $\mathbf{1 8}$ is frozen in liquid nitrogen and the frozen solution is irradiated at 363 $\mathrm{nm}$, the light emission increases markedly and, to the eye, it is as if a light were suddendly switched on. As the frozen solution starts to melt, the photoluminescence decays progressively.

Finally, it is worth noting that oligomers $\mathbf{1 - 1 5}$ have the same pseudosymmetry with one central thiophene- $S, S$-dioxide unit and one or two aromatic rings $\alpha$-linked at positions $\mathrm{C}-2$ and C-5. In our experience, these kinds of compounds have much greater photoluminescence efficiencies in the solid state than those having the oxygenated unit at, for example, one of the terminal positions. The reasons for this are to be explored, and theoretical calculations are currently under way, but of course, we cannot exclude that oligomers containing the oxygenated unit in different positions could also display high photoluminescence efficiencies and further increase the range of obtainable photoluminescence frequencies of these kinds of compounds.

(II) Electrochemical Measurements. Table 2 shows the first oxidation and reduction peak potentials obtained by cyclic voltammetry for representative oligomers of the series described in this report. For comparison, the oxidation and reduction peak potentials of unsubstituted thienylene and phenylene oligomers of comparable lengths are also reported. ${ }^{13}$

It can be seen that the presence of the thiophene- $S, S$-dioxide moiety leads to less negative reduction potentials and more positive oxidation potentials compared to those of corresponding thienylene and phenylene derivatives. For example, replacing two inner phenyl rings of hexaphenylene with one thiophene$S, S$-dioxide moiety (pentamer 7) leads to a reduction potential which is less negative by more than $600 \mathrm{mV}$ and to an oxidation potential which is more positive by about $400 \mathrm{mV}$ than that of hexaphenylene. Similar effects are observed when the inner phenyl group of terphenylene is replaced with one oxygenated unit (trimers $\mathbf{3}$ and $\mathbf{6}$ ). The same trend is also observed for the thiophene-based trimers $\mathbf{8 , 1 0}$ and pentamers 11, 13, 18, a trend similar to that previously described for a different series of oligothiophene- $S, S$-dioxides. ${ }^{6}$

The oxidation and reduction potentials of organic molecules give information on the HOMO and LUMO energies, respectively. In the case of photoluminescent molecules, these parameters are of paramount importance for the fabrication of electroluminescent devices. ${ }^{1,14}$

The data reported in Table 2 show that the insertion of the thiophene- $S, S$-dioxide unit decreases the energy of both the

(13) Meerholz, K.; Heinze, J. Electrochim. Acta 1996, 41, 1839. 
Scheme 2. Ionization Potentials and Electron Affinities of Compounds 3, 6-8, 10, 11, 13, 18, Ter- and Hexaphenylene (a), Ter- and Sexithiophene (b) Obtained from Electrochemical Oxidation and Reduction Peak Potentials (see Table 2)

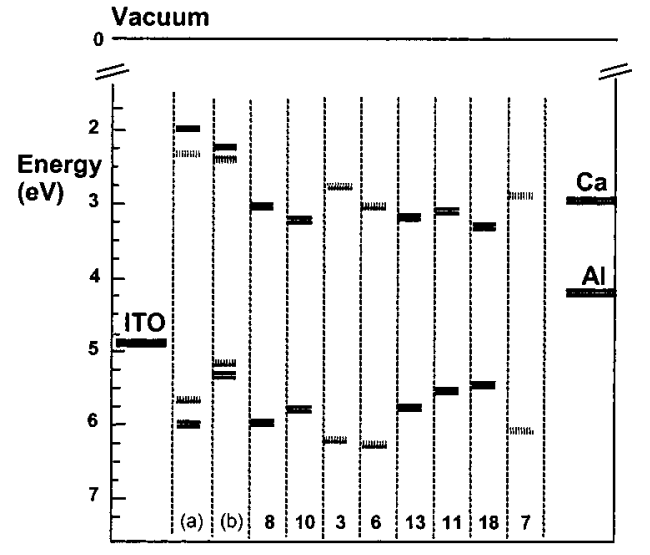

frontier orbitals in thiophene-based as well as phenyl-based oligomers. Moreover, since the LUMO energy is more affected than the HOMO energy, there is also a significant decrease in the HOMO-LUMO energy gap.

Scheme 2 shows a diagram of the ionization potentials and electron affinities of compounds $3,6-8, \mathbf{1 0}-\mathbf{1 1}, \mathbf{1 3}$, and 18 estimated $^{15}$ from the oxidation and reduction peak potentials obtained by cyclic voltammetry and shown in Table 2 . Scheme 2 also reports the work functions of aluminum and calcium and the work function of ITO which are generally used as the cathode and the anode materials, respectively, in the fabrication of electroluminescent devices. For comparison, the scheme also shows the ionization potentials and electron affinities of unsubstituted oligophenylenes (a) and oligothienylenes (b) determined from the corresponding oxidation and reduction potentials. $^{13}$

(III) Theoretical Calculations. We carried out B3LYP/6$31 \mathrm{G}^{*}$ ab initio calculations on the model dimers $2,2^{\prime}$-bithiophene1,1-dioxide (TO) and 2-phenyl-thiophene-1,1-dioxide (PO) which are the basic fragments of the compounds of Table 1 to estimate the importance of $\pi$-electron conjugation of the thienyl$S, S$-dioxide moiety with a thienyl and a phenyl ring, and the conformational preferences and the rotation barriers around the carbon-carbon inter-ring bond.

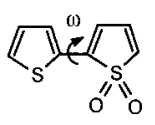

TO

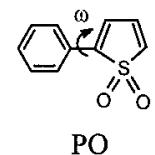

$\mathrm{PO}$
Figure 4 shows the rotational profile of $\mathrm{PO}$ and $\mathrm{TO}$ as a function of the torsion angle, $\omega$.

The rotational profile of TO is characterized by a very flat energy minimum for $\omega$ in the range $167-180^{\circ}$ corresponding to the antiltrans orientation between the thienyl and thienyl$S, S$-dioxide rings. A second relative energy minimum is found for $\omega=25^{\circ}$, corresponding to the syn orientation. We had already obtained similar results for TO using less refined calculations $\left(\mathrm{HF} / 6-31 \mathrm{G}^{*}\right){ }^{6 \mathrm{a}}$ The inclusion of electron correlation

(14) (a) Stössel, M.; Staudigel, J.; Steuber, F.; Simmerer, J.; A. Winnacker Appl. Phys. A 1999, 68, 387. (b) Stössel, M.; Staudigel, J.; Steuber, F.; Simmerer, J.; Wittmann, G.; Kanitz, A.; Klausmann, H.; Rogler, W.; Roth, W.; Schumann, J.; Winnacker, A. Phys. Chem. Chem. Phys. 1999, 1, 1791.

(15) Janietz, S.; Bradley, D. D. C.; Grell, M.; Giebeler, C.; Inbasekaran, M.; Woo, E. P. Appl. Phys. Lett. 1998, 73, 2453.

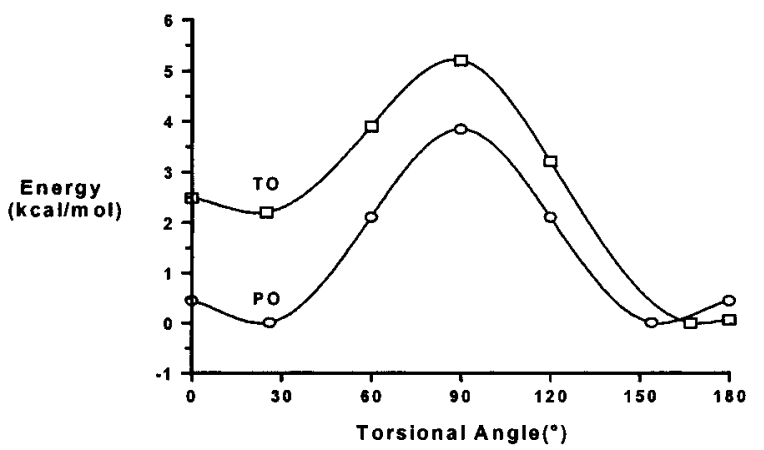

Figure 4. B3LYP/6-31G* ab initio calculated rotational profile of 2,2'bithiophene-1,1-dioxide (TO) and 2-phenyl-thiophene-1,1-dioxide (PO) as a function of the torsion angle.

by means of the hybrid density functional B3LYP allows obtaining more reliable values of the energy rotation barriers between the syn and anti orientations. ${ }^{16}$ For TO, the anti-anti energy barrier amounts to only $0.06 \mathrm{kcal} \mathrm{mol}^{-1}$, the syn-anti energy barrier is $5.2 \mathrm{kcal} \mathrm{mol}^{-1}$ and the syn-syn is $0.28 \mathrm{kcal}$ $\mathrm{mol}^{-1}$.

The rotational profile of $\mathrm{PO}$ is characterized by a well-defined energy minimum for $\omega=25^{\circ}$, indicating that PO is slightly more distorted than TO. The energy barriers for passing to the equi-energetic conformation with $\omega=-25^{\circ}$ (or $\omega=+155^{\circ}$ ) are $0.44 \mathrm{kcal} \mathrm{mol}^{-1}\left(+25^{\circ} / 0^{\circ} /-25^{\circ}\right)$ or $3.84 \mathrm{kcal} \mathrm{mol}^{-1}\left(+25^{\circ} /\right.$ $\left.90 \%+155^{\circ}\right)$.

The B3LYP/6-31G* calculated inter-ring carbon-carbon distances and overlap electronic densities are $1.434 \AA$ and 0.703 $\mathrm{e}^{-}$, respectively, for TO and $1.459 \AA$ and $0.687 \mathrm{e}^{-}$for $\mathrm{PO}$, showing that the thienyl-S,S-dioxide moiety gives rise to better $\pi-\pi$ electron conjugation with the thienyl than with the phenyl ring.

To have an insight into the influence of inter-ring distortion on conjugation, ZINDO/S calculations of the maximum absorption wavelengths of TO and PO were performed using fully planar geometries for both fragments. We obtained a $\lambda_{\max }$ value of $352 \mathrm{~nm}$ for TO and a much shorter $\lambda_{\max }$ value of $327 \mathrm{~nm}$ for $\mathrm{PO}$, indicating that the former fragment is intrinsically more conjugated than the latter.

To gain insight into the possible reasons why oligomers 1920 are not photoluminescent we calculated the geometry of trimer $\mathbf{1 9}$ and, for comparison, that of trimer $\mathbf{8}$ with the aid of MM3 calculations. The results are shown in Figure 5. Afterward, the $\lambda_{\max }$ values of both compounds were also calculated with the aid of ZINDO/S calculations, using the MM3 geometries.

The calculations show that the preferred conformation of $\mathbf{8}$ is very different from that of $\mathbf{1 9}$. While $\mathbf{8}$ is a nearly planar molecule, in $\mathbf{1 9}$ the presence of the tert-butyl substituents forces the adjacent thienyl groups to be nearly perpendicular to the plane of the inner unit. That MM3 calculated geometries are reliable is shown by the fact that ZINDO/S calculated $\lambda_{\max }$ values using these geometries are very close to the experimental ones for both $19\left(\lambda_{\text {maxcalc }}=322 \mathrm{~nm}, \lambda_{\text {maxexp }}=336 \mathrm{~nm}\right)$ and 8 $\left(\lambda_{\text {maxcalc }}=411 \mathrm{~nm}, \lambda_{\operatorname{maxexp}}=412 \mathrm{~nm}\right)$.

\section{Discussion}

Our data shows that the solid-state photoluminescence frequency of a thiophene- $S, S$-dioxide moiety under UV excitation can be finely tuned across the entire visible range with a great variety of shades and with good solid-state photoluminescence efficiencies in all color ranges. Given the richness of

(16) Bongini, A.; Bottoni, A. J. Phys. Chem. A 1999, 6800. 

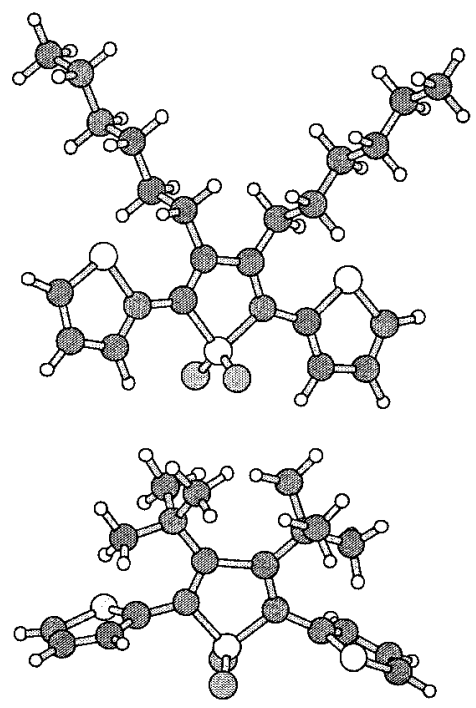

Figure 5. MM3 calculated geometries of trimers 8 and 19 .

substituents that can be grafted to the oxygenated unity and to the different positions of the attached aromatic rings, it is easily argued that the color shades of the picture of Figure 2 are only a few of those which could be obtained. Thus, very fine color resolution may be achieved with these kinds of materials while the photoluminescence efficiencies can reach values as high as $70 \%$ (compound 7 , to our knowledge, has one of the highest solid-state efficiencies ever measured for organic molecules). Moreover, blends of these compounds can nicely extend the colors of light emission (see, for example, the magenta colors in Figure 2) and even give rise to white photoluminescence. ${ }^{12}$

Compared to other important classes of thienylene-based, ${ }^{1 \mathrm{c}}$ phenylene-based, ${ }^{\text {if }}$ or thienylene/phenylene-based ${ }^{4 \mathrm{~b}}$ materials, the compounds reported here are characterized by greater solidstate photoluminescence quantum efficiencies and greater electron affinities.

We can look at these oligomers as phenylene or thienylene derivatives containing in the main chain one nonaromatic thiophene- $S, S$-dioxide or as butadiene derivatives whose emission frequency is modulated by changing the aromatic residue attached at the terminal positions. Unsubstituted butadiene does not display photoluminescence, but its 1,4-diphenyl derivative does. ${ }^{17}$ Whatever the more correct view of these compounds is, the key factor is the presence of the oxygen atoms on sulfur, which allows control of the photoluminescence efficiency and frontier orbital energies in particular that of the LUMO, that is, of the electron affinity. In this respect, it is remarkable that the replacement of the two inner phenyl groups of hexaphenylene with one thienyl-S,S-dioxide moiety as in compound 7 , increases the photoluminescence efficiency from $30 \%^{1 \mathrm{~g}}$ to $70 \%$ and increases the electron affinity by more than $0.5 \mathrm{~V}$.

Scheme 2 shows that the frontier orbital energies of the oligomers containing the central thienyl-S,S-dioxide unit are markedly displaced toward more negative values (with respect to the vacuum level) compared to those of corresponding unsubstituted phenylene (a) or thienylene (b) oligomers, indicating the increase of both the electron affinities and the ionization potentials in these kinds of materials. Conventional thienylene and phenylene oligomers are $p$-type semiconductor materials with low electron affinities. Finding a kind of functionalization capable of increasing their electron affinity is a necessary step to make these materials more suitable for the fabrication of

(17) (a) Orlandi, G.; Zerbetto, F.; Zgierski, M. Z. Chem. Rev. 1991, 91, 867. (b) Zerbetto, F. J. Am. Chem. Soc. 1995, 117, 1621. electroluminescent devices. Indeed, the greater the electron affinity of the light-emitting material is, the smaller is the energy barrier between the LUMO and the Fermi level of the metal used as the cathode, leading to better electron injection and increased device performance ${ }^{14,1}$ In the case of oligothiophene$S, S$-dioxides we have been able to demonstrate that lightemitting diodes fabricated with pentamers $\mathbf{1 1}$ and $\mathbf{1 3}$ are characterized by high electroluminescence efficiencies and low turn on voltages, thus opening the door to the use of thiophenebased oligomers as active materials in LED technology. ${ }^{6 \mathrm{~d}, \mathrm{e}}$ Studies of the electroluminescence efficiencies of the other compounds of Table 1 are currently under way.

The data reported in Table 1 show that the photoluminescence frequency of compounds $\mathbf{1 - 1 5}$ is related to the oligomer length and to the backbone $\pi$-electron delocalization.

Owing to the presence of the oxygenated moiety which increases the $\pi$-electron delocalization of oligothiophenes, ${ }^{6 a}$ it was not possible to obtain blue light emission using "all-thienyl" oligomers. Intense blue photoluminescence was only obtained with monomer 1, whereas longer oligomers were photoluminescent in the yellow, orange, and red regions, with high quantum efficiencies.

The attempt to obtain blue photoluminescence by causing very large backbone distortions through the introduction of bulky tert-butyl groups failed, as trimer $\mathbf{1 9}$ and pentamer $\mathbf{2 0}$ (see Scheme 1) did not show any photoluminescence in the visible, neither in the solid state nor in solution. A further attempt to distribute the degree of backbone distortion over the entire molecule by replacing the 3,4-di-tert-butyl substituents with neopentyl groups and grafting at the same time head-to-head neopentyl groups on the adjacent thienyl rings as in pentamer 12 was again unsuccessful. Despite the many bulky substituents, $\pi$-electron conjugation is still very efficient in $\mathbf{1 2}$, and photoluminescence in the orange region was obtained.

$\mathrm{Ab}$ initio calculations of the thienyl-thienyl-S,S-dioxide (TO) and phenyl-thienyl-S,S-dioxide (PO) fragments showed that $\pi$-electron conjugation in PO is smaller than in TO. Thus, oligomers having phenyl rather than thienyl groups $\alpha$-linked to the central oxygenated moiety were synthesized. Table 1 shows that these kinds of compounds have indeed smaller absorption and photoluminescence wavelengths than their "all-thienyl" counterparts. In this way pale-blue/green-yellow very efficient light emissions were obtained with oligomers 2-7.

Polymerization of all-thienyl" oligomers such as trimer $\mathbf{9}$ and pentamer 13 afforded polymers which emit light in the near-IR (P3 and P5, see Figure 1 and Table 1). It is worth noting that polymer P5 is reversibly $p$ - and $n$-dopable at moderate potential values. ${ }^{6 \mathrm{c}}$ Unfortunately, the quantum photoluminescence efficiencies measured for the microcrystalline powders of $\mathbf{P 3}$ and P5 are only of a few percent, probably due to unfavorable morphology characteristics. Nevertheless, the extreme synthetic flexibility associated with the preparation of polymers containing oxygenated thienyl groups ${ }^{6 c, 7}$ looks encouraging for the search of electroactive polymers with light emission frequencies tunable in the near-IR and high solid-state photoluminescence quantum efficiencies.

It is not straightforward to account for the variations in photoluminescence quantum efficiency observed for our oligomers since this parameter is the result of a complex relationship of individual properties and collective behavior. The light emission process is determined by the probability of radiative compared to non radiative transitions from the excited to the ground state, and there are numerous possible pathways for 
nonradiative emission. ${ }^{10,18}$ Nevertheless, from our data, a few indications on the relationship existing between the molecular structure and the photoluminescence efficiency can be derived.

In conventional thiophene oligomers, strong intermolecular interactions in the solid state lead to the quenching of photoluminescence. ${ }^{8 \mathrm{a}, 18}$ In oligothiophene-S,S-dioxides the presence of the strongly dipolar sulfonyl group introduces other kinds of intermolecular interactions which counteract the tendency to organize in parallel layers and then decreases the number of possible nonradiative patterns for energy relaxation from the singlet excited state arising from strong intermolecular interactions. ${ }^{19}$

However, also in oligothiophene-S,S-dioxides strong intermolecular interactions in the solid state may lead to photoluminescence quenching. This is clearly the case of pentamer $\mathbf{1 8}$ (Scheme 1) which, contrary to its regioisomer 13 (Table 1), is not photoluminescent in the solid state but is photoluminescent in solution where it behaves in much the same way as $\mathbf{1 3}$ itself (see Figure 3). It is likely that $\mathbf{1 8}$, which, according to its $\lambda_{\max }$ value $(493 \mathrm{~nm})$ even in solution is more planar than $\mathbf{1 3}$, adopts a fully coplanar conformation in the solid state with the alkyl chains pointing in opposite directions and a molecular packing similar to that of the alkylated conventional oligothiophenes with the same regiochemistry of substitution. ${ }^{20}$

The results relative to oligomers $\mathbf{1 3}$ and $\mathbf{1 8}$ indicate that control of self-assembly and thus of solid-state photoluminescence may be obtained by changing the regiochemistry of substitution, while control of photoluminescence in solution may be obtained by changing the solvent. To our knowledge, conventional oligothiophenes display only very little, if any, solvent dependence of photoluminescence.

Among those that we have synthesized, only the oligomers bearing 3,4-tert-butyl substituents (19 and 20, see Scheme 1) do not display any photoluminescence in the visible region, neither in the solid state nor in solution, as mentioned above. It is likely that in this case it is the large backbone distortion caused by the bulky substituents (see Figure 5) that causes the dominance of nonradiative over radiative pathways. If so, compounds 19, 20 on one side and 17, 18 on the other side represent two extreme cases of dominance of intrinsic molecular features and solid-state intermolecular interactions in determining photoluminescence properties.

A question which remains unanswered is why the oligomers having phenyl groups $\alpha$-linked to the oxygenated unit display much higher photoluminescence efficiencies than those with $\alpha$-linked thienyl groups. Compare, for example, trimer 8 ( $\eta=$ $45 \%)$ with trimer $3(\eta=63 \%)$ and pentamer $13(\eta=12 \%)$ with pentamer $7(\eta=70 \%)$.

It is likely that part of the difference comes from different packing arrangements, but at this time no X-ray data are available on phenylene derivatives bearing thiophene- $S, S$-dioxide moieties. Our chemical intuition would tend to ascribe a large part of the difference not only to intersystem crossing mechanisms (ISC, formation of triplet excitons) related to the presence of the heavy sulfur atom ${ }^{18}$ but also to the greater "plasticity" $6 f$ of thienylene compared to phenylene rings. In other words, we feel that the occurrence of geometry relaxation phenomena due to the great polarizability of the sulfur atom and to the

(18) (a) Beljonne, D.; Cornil, J.; Friend, R. H.; Jansen, R. A. J.; Brédas, J. L. J. Am. Chem. Soc. 1996, 118, 6453. (b) Brédas, J. L.; Cornil, J.; Beljonne, D.; Dos Santos, D. A.; Shuai, Z. Acc. Chem. Res. 1999, 32, 267.

(19) Antolini, L.; Tedesco, E.; Barbarella, G.; Favaretto, L.; Sotgiu, G.; Zambianchi, M.; Casarini, D.; Gigli, G.; Cingolani, R. J. Am. Chem. Soc. 2000, $122,9006$.

(20) Herrema, J. K.; Wildeman, J.; van Bolhuis, F.; Hadziioannou, G. Synth. Met. 1993, 60, 239. consequently easy bond lengths and bond-angle deformability must be important, that is, that nonradiative internal conversion mechanisms (IC, decay to the ground state through the emission of vibrational quanta ${ }^{18}$ ) should play a major role in thiophenebased molecules. On the other hand, the fact that the rotational profiles of PO and TO are very similar (see Figure 4) seems to exclude major contributions to the IC mechanism arising from different rotation barriers around the carbon-carbon bonds between phenylene-based and thienylene-based oligomers. Clearly, unambiguous interpretations of photoluminescence quantum yields of compounds containing one central thienyl$S, S$-dioxide moiety must wait for time-resolved photoluminescence experiments to be carried out.

\section{Conclusions}

We have shown that starting from a nonaromatic thiophene$S, S$-dioxide unity it is possible to build a new family of oligomers which emit light under UV excitation with frequencies covering the entire visible range. All of these compounds display higher electron affinities than conventional oligothiophenes and oligophenylenes of comparable size.

The importance of small luminescent molecules for the fabrication of thin film light-emitting devices has been recently outlined by several authors. ${ }^{1 \mathrm{e}, 3}$ However, we call attention to the fact that soluble, chemically stable, easily functionalized, organic compounds which are highly luminescent in all colors of the visible range are also important for applications as markers for molecules of biological interest, a field in which presently we are actively involved.

\section{Experimental Section}

Synthesis of Materials. The synthesis and the characterization of compound $\mathbf{1}$ is given in ref $6 \mathrm{~g}$, that of compounds $\mathbf{8 , 1 3}$, and $\mathbf{1 6}$ in ref $6 \mathrm{c}$ and that of compound $\mathbf{1 1}$ in ref $6 \mathrm{~d}$. The synthesis and the electrochemical characterization of polymer P5 is reported in ref 6c. Polymer $\mathbf{P 3}$ was synthesized and purified starting from trimer $\mathbf{9}$ and using the same modalities employed for the synthesis of polymer P5. ${ }^{60}$ 2,5-Dibromo-3,4-di(tert-butyl)thiophene was prepared according to Nakayama et al. ${ }^{21}$ All oligomers were synthesized by reacting a 2,5dibromo-thiophene-S,S-dioxide or 2,5-dibromo-3,4-dialkyl(aryl)thiophene$S, S$-dioxide moiety with the appropriate monostannane according to the modalities described in ref $6 a$.

2,5-Bis(phenyl)-3,4-dimethyl-thiophene-1,1-dioxide, 2: Yellow bright microcrystalline powder; mp $200{ }^{\circ} \mathrm{C}$; MS (70 eV, EI): m/e 296 $\left(\mathrm{M}^{\circ+}\right)$; IR $\left(\mathrm{SO}_{2}\right): 1283,1138 \mathrm{~cm}^{-1} ; 56 \%$ yield. ${ }^{1} \mathrm{H} \mathrm{NMR}\left(\mathrm{CDCl}_{3}\right): \delta$ $\mathrm{ppm}=7.6(\mathrm{~m}, 4 \mathrm{H}), 7.5(\mathrm{~m}, 6 \mathrm{H}), 2.15(\mathrm{~s}, 6 \mathrm{H}) .{ }^{13} \mathrm{C} \mathrm{NMR}\left(\mathrm{CDCl}_{3}\right): \delta$ $\mathrm{ppm}=136.0,135,3,129.5,129.2,129.0,127.5,12.9$. Anal. Calcd for $\mathrm{C}_{18} \mathrm{H}_{16} \mathrm{O}_{2} \mathrm{~S}$ : C, 72.94; H, 5.44. Found: C, 72.77; H, 5.46.

2,5-Bis(phenyl)-3,4-di(n-hexyl)-thiophene-1,1-dioxide, 3: Bright yellow microcrystalline powder; $\mathrm{mp} 91^{\circ} \mathrm{C}$; $\mathrm{MS}(70 \mathrm{eV}, \mathrm{EI}): \mathrm{m} / \mathrm{e} 436$ $\left(\mathrm{M}^{\bullet+}\right)$. IR $\left(\mathrm{SO}_{2}\right): 1282,1138 \mathrm{~cm}^{-1} ; 95 \%$ yield. ${ }^{1} \mathrm{H} \mathrm{NMR}\left(\mathrm{CDCl}_{3}\right): \delta$ $\mathrm{ppm}=7.6(\mathrm{~m}, 4 \mathrm{H}), 7.5(\mathrm{~m}, 6 \mathrm{H}), 2.5(\mathrm{~m}, 4 \mathrm{H}), 1.5(\mathrm{~m}, 4 \mathrm{H}), 1.3(\mathrm{~m}$, $12 \mathrm{H}), 0.85(\mathrm{~m}, 6 \mathrm{H}) .{ }^{13} \mathrm{C} \mathrm{NMR}\left(\mathrm{CDCl}_{3}\right): \delta \mathrm{ppm}=140.0,136.0,129.5$, 129.4, 129.0, 127.7, 31.2, 29.3, 29.2, 26.2, 22.4. Anal. Calcd for $\mathrm{C}_{28} \mathrm{H}_{36} \mathrm{O}_{2} \mathrm{~S}$ : C, 77.02; H, 8.31. Found: $\mathrm{C}, 77.25 ; \mathrm{H}, 8.32$.

2,5-Bis(phenyl)-3,4-di(neo-pentyl)-thiophene-1,1-dioxide, 4: Orange bright microcrystalline powder; $\mathrm{mp} 250{ }^{\circ} \mathrm{C}$; MS (70 eV, EI): m/e $408\left(\mathrm{M}^{\bullet+}\right)$; IR $\left(\mathrm{SO}_{2}\right): 1292,1130 \mathrm{~cm}^{-1} ; 55 \%$ yield. ${ }^{1} \mathrm{H} \mathrm{NMR}\left(\mathrm{CDCl}_{3}\right)$ : $\delta \mathrm{ppm}=7.6(\mathrm{~m}, 4 \mathrm{H}), 7.4(\mathrm{~m}, 6 \mathrm{H}), 2.7(\mathrm{~s}, 4 \mathrm{H}), 0.8(\mathrm{~s}, 18 \mathrm{H}) .{ }^{13} \mathrm{C} \mathrm{NMR}$ $\left(\mathrm{CDCl}_{3}\right): \delta \mathrm{ppm}=139.0,137.3,129.7,129.4,129.0,128.7,38.3,35.2$, 30.2. Anal. Calcd for $\mathrm{C}_{26} \mathrm{H}_{32} \mathrm{O}_{2} \mathrm{~S}$ : C, 76.43; H, 7.89. Found: C, 76.66; $\mathrm{H}, 7.91$.

2,5-Bis(phenyl)-thiophene-1,1-dioxide, 5: Yellow bright microcrystalline powder.; mp $170{ }^{\circ} \mathrm{C}$; $\mathrm{MS}(70 \mathrm{eV}, \mathrm{EI}):$ m/e $268\left(\mathrm{M}^{\circ+}\right)$; IR $\left(\mathrm{SO}_{2}\right): 1293,1136 \mathrm{~cm}^{-1} ; 52 \%$ yield. ${ }^{1} \mathrm{H}$ NMR $\left(\mathrm{CDCl}_{3}\right): \delta \mathrm{ppm}=$ $7.02(\mathrm{~s}, 2 \mathrm{H}), 7.8(\mathrm{~m}, 4 \mathrm{H}), 7.45(\mathrm{~m}, 6 \mathrm{H}) .{ }^{13} \mathrm{C} \mathrm{NMR}\left(\mathrm{CDCl}_{3}\right): \delta=141.8$, 
130.3, 129.3, 127.2, 126.4, 120.5. Anal. Calcd for $\mathrm{C}_{16} \mathrm{H}_{14} \mathrm{O}_{2} \mathrm{~S}:$ C, 71.08 ; H, 5.22. Found: C, 70.93; H, 5.24.

2,5-Bis(phenyl)-3,4-diphenyl-thiophene-1,1-dioxide, 6: Yellow bright microcrystalline powder; $\mathrm{mp} 235^{\circ} \mathrm{C}$; MS (70 eV, EI): m/e 420 $\left(\mathrm{M}^{\bullet+}\right)$; IR $\left(\mathrm{SO}_{2}\right): 1292,1139 \mathrm{~cm}^{-1} ; 73 \%$ yield. ${ }^{1} \mathrm{H} \mathrm{NMR}\left(\mathrm{CDCl}_{3}\right): \delta$ $\mathrm{ppm}=7.45(\mathrm{~m}, 4 \mathrm{H}), 7.2(\mathrm{~m}, 12 \mathrm{H}), 6.9(\mathrm{~m}, 4 \mathrm{H}) .{ }^{13} \mathrm{C} \mathrm{NMR}\left(\mathrm{CDCl}_{3}\right)$ : $\delta \mathrm{ppm}=138.4,136.1,131.7,129.6,129.5,129.4,128.8,128.7,128.4$, 127.3. Anal. Calcd for $\mathrm{C}_{28} \mathrm{H}_{20} \mathrm{O}_{2} \mathrm{~S}:$ C, 79.97; H, 4.79. Found C, 80.05; $\mathrm{H}, 4.80$

2,5-Bis(p-biphenyl)-3,4-dihexyl-thiophene-1,1-dioxide, 7: Yellowgreen microcrystalline powder; mp $100{ }^{\circ} \mathrm{C}$; MS (70 eV, EI): m/e 588 $\left(\mathrm{M}^{\bullet+}\right)$; IR $\left(\mathrm{SO}_{2}\right): 1287,1141 \mathrm{~cm}^{-1} ; 64 \%$ yield. ${ }^{1} \mathrm{H} \mathrm{NMR}\left(\mathrm{CDCl}_{3}\right): \delta$ $\mathrm{ppm}=7.65(\mathrm{~m}, 12 \mathrm{H}), 7.45(\mathrm{~m}, 6 \mathrm{H}), 2.5(\mathrm{~m}, 4 \mathrm{H}), 1.6(\mathrm{~m}, 4 \mathrm{H}), 1.3(\mathrm{~m}$, $12 \mathrm{H}), 0.85(\mathrm{~m}, 6 \mathrm{H}) .{ }^{13} \mathrm{C} \mathrm{NMR}\left(\mathrm{CDCl}_{3}\right): \delta \mathrm{ppm}=142.3,140.3,140.0$ $135.8,129.6,128.9,127.8,127.6,127.1,126.5,31.2,29.3,26.3,22.4$, 13.9. Anal. Calcd for $\mathrm{C}_{40} \mathrm{H}_{44} \mathrm{O}_{2} \mathrm{~S}: \mathrm{C}, 81.59 ; \mathrm{H}, 7.53$. Found: $\mathrm{C}, 81.31$; $\mathrm{H}, 7.51$

$3^{\prime} 4^{\prime}$-Dimethyl-2,2':5', $\mathbf{2}^{\prime \prime}$-terthiophene-1',1'-dioxide, 9: Light orange microcrystalline powder; mp $162{ }^{\circ} \mathrm{C}$; MS $(70 \mathrm{eV}, \mathrm{EI}): \mathrm{m} / \mathrm{e} 308\left(\mathrm{M}^{+}\right)$; IR $\left(\mathrm{SO}_{2}\right): 1288,1140 \mathrm{~cm}^{-1} ; 80 \%$ yield. ${ }^{1} \mathrm{H} \mathrm{NMR}\left(\mathrm{CDCl}_{3}\right): \delta \mathrm{ppm}=$ 7.69 (doublet of doublets, $J=3.7 \mathrm{~Hz}, J=1.0 \mathrm{~Hz}, 2 \mathrm{H}$ ), 7.52 (doublet of doublets, $J=5.1 \mathrm{~Hz}, J=1.0 \mathrm{~Hz}, 2 \mathrm{H}$ ), 7.19 (doublet of doublets, $J=3.7 \mathrm{~Hz}, J=5.1 \mathrm{~Hz}, 2 \mathrm{H}), 2.3(\mathrm{~s}, 6 \mathrm{H}) .{ }^{13} \mathrm{C} \mathrm{NMR}\left(\mathrm{CDCl}_{3}\right): \delta \mathrm{ppm}$ $=133.6,130.5,129.0,128.6,128.2,128.0,13.5$. Anal. Calcd for $\mathrm{C}_{24} \mathrm{H}_{16} \mathrm{O}_{2} \mathrm{~S}_{3}$ : C, 66.64; $\mathrm{H}, 3.73$. Found: $\mathrm{C}, 66.60 ; \mathrm{H}, 3.73$.

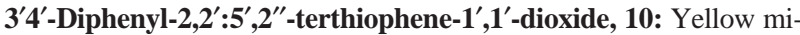
crocrystalline powder; mp $249^{\circ} \mathrm{C}$; MS $(70 \mathrm{eV}, \mathrm{EI})$ : m/e $432\left(\mathrm{M}^{++}\right)$; IR $\left(\mathrm{SO}_{2}\right): 1303,1146 \mathrm{~cm}^{-1} ; 75 \%$ yield. ${ }^{1} \mathrm{H}$ NMR $\left(200 \mathrm{MHz}, \mathrm{CDCl}_{3}\right.$, TMS): $\delta=7.77$ (doublet of doublets, $\mathrm{J}(\mathrm{H}, \mathrm{H})=1.0 \mathrm{~Hz}, \mathrm{~J}(\mathrm{H}, \mathrm{H})=3.8$ $\mathrm{Hz}, 2 \mathrm{H}), 7.29(\mathrm{~m}, 8 \mathrm{H}), 7.12(\mathrm{~m}, 4 \mathrm{H}), 7.08$ (doublet of doublets, $\mathrm{J}(\mathrm{H}, \mathrm{H})$ $=3.8 \mathrm{~Hz}, \mathrm{~J}(\mathrm{H}, \mathrm{H})=5.1 \mathrm{~Hz}, 2 \mathrm{H}) .{ }^{13} \mathrm{C} \mathrm{NMR}\left(50 \mathrm{MHz}, \mathrm{CDCl}_{3}, \mathrm{TMS}\right)$ : $\delta=135.3,131.4,131.0,129.4,129.1,129.08,129.05,128.9,128.8$, 127.3. Anal. Calcd for $\mathrm{C}_{24} \mathrm{H}_{16} \mathrm{O}_{2} \mathrm{~S}_{3}: \mathrm{C}, 66.64 ; \mathrm{H}, 3.73$. Found: $\mathrm{C}, 66.51$; $\mathrm{H}, 3.74$.

$3,3^{\prime}, 3^{\prime \prime}, 4^{\prime \prime}, 4^{\prime \prime \prime}, 3^{\prime \prime \prime \prime}$-Hexa(neo-pentyl)-2,2':5',2" $: 5^{\prime \prime}, 2^{\prime \prime \prime}: 5^{\prime \prime}, 2^{\prime \prime \prime \prime}$-quinquethiophene-1", $1^{\prime \prime}$-dioxide, 12: Bright orange microcrystalline powder; mp $186{ }^{\circ} \mathrm{C}$; $\mathrm{MS}(70 \mathrm{eV}, \mathrm{EI}):$ m/e $864\left(\mathrm{M}^{\bullet+}\right)$; IR $\left(\mathrm{SO}_{2}\right)$ : 1298 , $1144 \mathrm{~cm}^{-1} ; 12 \%$ yield. ${ }^{1} \mathrm{H}$ NMR $\left(\mathrm{CD}_{2} \mathrm{Cl}_{2}\right): \delta \mathrm{ppm}=7.57(\mathrm{~s}, 2 \mathrm{H})$, 7.39 (d, $J=5.2 \mathrm{~Hz}, 2 \mathrm{H}), 7.03(\mathrm{~d}, J=5.2 \mathrm{~Hz}, 2 \mathrm{H}), 2.92(\mathrm{~s}, 4 \mathrm{H}), 2.52$ (s, 4H), $2.50(\mathrm{~s}, 4 \mathrm{H}), 0.98(\mathrm{~s}, 9 \mathrm{H}), 0.88(\mathrm{~s}, 18 \mathrm{H}) .{ }^{13} \mathrm{C} \mathrm{NMR}\left(\mathrm{CD}_{2} \mathrm{Cl}_{2}\right)$ : $\delta \mathrm{ppm}=140.0,139.9,137.6,134.1,133.1,131.6,130.7,129.7,128.4$, 125.4, 42.8, 42.5, 39.2, 36.2, 32.9, 32.7, 30.2, 30.0, 29.9. Anal. Calcd for $\mathrm{C}_{50} \mathrm{H}_{72} \mathrm{O}_{2} \mathrm{~S}_{5}$ : C, 69.39; H, 8.39. Found: $\mathrm{C}, 69.13 ; \mathrm{H}, 8.37$.

$3,3^{\prime}, 3^{\prime \prime}, 4^{\prime \prime}, 4^{\prime \prime \prime}, 3^{\prime \prime \prime \prime}-$ Hexamethyl-2, $2^{\prime}: 5^{\prime}, 2^{\prime \prime}: 5^{\prime \prime}, 2^{\prime \prime \prime}: 5^{\prime \prime \prime}, 2^{\prime \prime \prime \prime}$-quinquethiophene-1"1"1"-dioxide, 14: Bright orange microcrystalline powder; mp 210 ; MS (70 eV, EI): $m / e ~ 528\left(\mathrm{M}^{+}\right)$; IR $\left(\mathrm{SO}_{2}\right): 1297,1138 \mathrm{~cm}^{-1}$; $80 \%$ yield. ${ }^{1} \mathrm{H}$ NMR $\left(\mathrm{CDCl}_{3}\right): \delta \mathrm{ppm}=7.6(\mathrm{~s}, 2 \mathrm{H}), 7.3(\mathrm{~d}, J=5.1$ $\mathrm{Hz}, 2 \mathrm{H}), 6.9$ (d, $J=5.1 \mathrm{~Hz}, 2 \mathrm{H}), 2.3(\mathrm{~s}, 6 \mathrm{H}), 2.23$ (s, 6H), 2.22 (s, $6 \mathrm{H}) .{ }^{13} \mathrm{C} \mathrm{NMR}\left(\mathrm{CDCl}_{3}\right): \delta \mathrm{ppm}=137.2,137.1,133.0,132.9,131.5$, 130.3, 130.1, 128.1, 128.0, 125.8, 14.8, 14.7, 13.7. Anal. Calcd for $\mathrm{C}_{36} \mathrm{H}_{28} \mathrm{O}_{2} \mathrm{~S}_{5}: \mathrm{C}, 66.22 ; \mathrm{H}, 4.32$. Found $\mathrm{C}, 66.07 ; \mathrm{H}, 4.34$

$3,3^{\prime}, 4^{\prime \prime \prime}, 3^{\prime \prime \prime \prime}-$ Tetramethyl-3", $4^{\prime \prime}$-diphenyl-2, $2^{\prime}: 5^{\prime}, 2^{\prime \prime}: 5^{\prime \prime}, 2^{\prime \prime \prime}: 5^{\prime \prime \prime}, 2^{\prime \prime \prime \prime}$. quinquethiophene-1" $\mathbf{1}^{\prime \prime}$-dioxide, $\mathbf{1 5}$. Red microcrystalline powder; mp $147{ }^{\circ} \mathrm{C}$; MS $(70 \mathrm{eV}, \mathrm{EI})$ : m/e $652\left(\mathrm{M}^{\circ+}\right)$; IR $\left(\mathrm{SO}_{2}\right): 1297,1138$ $\mathrm{cm}^{-1} ; 60 \%$ yield. ${ }^{1} \mathrm{H}$ NMR $\left(\mathrm{CDCl}_{3}\right): \delta \mathrm{ppm}=7.60(\mathrm{~s}, 2 \mathrm{H}), 7.28(\mathrm{~m}$, $8 \mathrm{H}), 7.17(\mathrm{~m}, 4 \mathrm{H}), 6.89(\mathrm{~d}, J=5.1 \mathrm{~Hz}, 2 \mathrm{H}), 2.18(\mathrm{~s}, 6 \mathrm{H}), 2.08(\mathrm{~s}$, $6 \mathrm{H}) .{ }^{13} \mathrm{C}$ NMR $\left(\mathrm{CDCl}_{3}\right): \delta \mathrm{ppm}=137.4,135.8,134.5,132.5,132.0$, 131.3, 130.7, 129.7, 129.6, 129.2, 128.9, 128.4, 126.1, 14.9, 14.8. Anal. Calcd for $\mathrm{C}_{36} \mathrm{H}_{28} \mathrm{O}_{2} \mathrm{~S}_{5}$ : C, 66.22; H, 4.32. Found $\mathrm{C}, 66.07 ; \mathrm{H}, 4.34$.

3,3"-Di(hexyl)-2,2':5',2"'-terthiophene-1',1'-dioxide, 17: Orange powder; $\mathrm{mp} 77^{\circ} \mathrm{C}$; MS $(70 \mathrm{eV}, \mathrm{EI})$ : m/e $448\left(\mathrm{M}^{\circ+}\right) ; \lambda_{\max }\left(\mathrm{CHCl}_{3}\right)=$ $422 \mathrm{~nm} ; 13 \%$ yield. ${ }^{1} \mathrm{H}$ NMR $\left(\mathrm{CDCl}_{3}\right): \delta \mathrm{ppm}=7.44\left(J_{\mathrm{AB}}=5.2 \mathrm{~Hz}\right.$, $2 \mathrm{H}), 7.03\left(J_{\mathrm{AB}}=5.2 \mathrm{~Hz}, 2 \mathrm{H}\right), 6.76(\mathrm{~s}, 2 \mathrm{H}), 2.76(\mathrm{t}, 4 \mathrm{H}) 1.65(\mathrm{~m}, 4 \mathrm{H})$, $1.33(\mathrm{~m}, 8 \mathrm{H}), 0.89(\mathrm{t}, 6 \mathrm{H}) .{ }^{1} \mathrm{H}$ NMR $\left(\mathrm{CDCl}_{3}\right): \delta \mathrm{ppm}=146.0,139.4$, 136.4, 130.0, 128.3, 121.7, 31.7, 30.4, 30.0, 29.2, 22.6, 14.1. Anal. Calcd for $\mathrm{C}_{24} \mathrm{H}_{32} \mathrm{O}_{2} \mathrm{~S}_{3}$ : C, 64.24; H, 7.19; Found C, 64.14; H, 7.15.

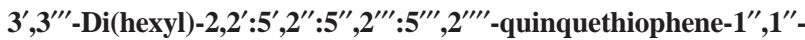
dioxide, 18: Red powder; $\mathrm{mp} 124{ }^{\circ} \mathrm{C}$; MS (70 eV, EI): m/e $612\left(\mathrm{M}^{++}\right)$; IR $\left(\mathrm{SO}_{2}\right): 1296,1139 \mathrm{~cm}^{-1} ; \lambda_{\max }\left(\mathrm{CHCl}_{3}\right)=493 \mathrm{~nm} ; 17 \%$ yield. ${ }^{1} \mathrm{H}$ NMR (acetone- $d_{6}$, TMS): $\delta \mathrm{ppm}=7.50$ (doublet of doublets, $\mathrm{J}(\mathrm{H}, \mathrm{H})$ $=5.1 \mathrm{~Hz}, \mathrm{~J}(\mathrm{H}, \mathrm{H})=1.0 \mathrm{~Hz}, 2 \mathrm{H}), 7.41$ (doublet of doublets, $\mathrm{J}(\mathrm{H}, \mathrm{H})=$
$3.7 \mathrm{~Hz}, \mathrm{~J}(\mathrm{H}, \mathrm{H})=1.0 \mathrm{~Hz}, 2 \mathrm{H}), 7.34(\mathrm{~s}, 2 \mathrm{H}), 7.15(\mathrm{~s}, 2 \mathrm{H}), 7.12$ (doublet of doublets, $\mathrm{J}(\mathrm{H}, \mathrm{H})=5.1 \mathrm{~Hz}, \mathrm{~J}(\mathrm{H}, \mathrm{H})=3.7 \mathrm{~Hz}, 2 \mathrm{H}), 2.81(\mathrm{~m}, 4 \mathrm{H})$, $1.72(\mathrm{~m}, 4 \mathrm{H}), 1.35(\mathrm{~m}, 8 \mathrm{H}), 0.88(\mathrm{t}, 6 \mathrm{H}) .{ }^{13} \mathrm{CNMR}\left(\mathrm{CDCl}_{3}\right): \delta \mathrm{ppm}=$ $146.9,140.1,136.5,135.5,128.1,126.5,125.5,124.8,121.3,121.1$, 31.7, 30.3, 30.2, 29.3, 22.6, 14.1. Anal. Calcd for $\mathrm{C}_{32} \mathrm{H}_{36} \mathrm{O}_{2} \mathrm{~S}_{5}$ : C,62.71; H, 5.92; Found C,62.91; H, 5.92.

$3^{\prime} 4^{\prime}$-Di(tert-butyl)-2,2':5',2'-terthiophene-1', $\mathbf{1}^{\prime}$-dioxide, 19: Pale yellow solid, mp $226^{\circ} \mathrm{C}$; MS (70 eV, EI): m/e $392\left(\mathrm{M}^{++}\right)$; IR $\left(\mathrm{SO}_{2}\right)$ : $1292,1136 \mathrm{~cm}^{-1} ; \lambda_{\max }\left(\mathrm{CHCl}_{3}\right)=336 \mathrm{~nm} ; 30 \%$ yield. ${ }^{1} \mathrm{H} \mathrm{NMR}\left(\mathrm{CDCl}_{3}\right.$, TMS): $\delta \mathrm{ppm}=7.54$ (doublet of doublets, $J=1.2 \mathrm{~Hz}, J=5.2 \mathrm{~Hz}$, $2 \mathrm{H}$ ); 7.38 (doublet of doublets, $J=1.2 \mathrm{~Hz}, J=3.6 \mathrm{~Hz}, 2 \mathrm{H}$ ); 7.14 (doublet of doublets, $J=5.2 \mathrm{~Hz}, J=3.6 \mathrm{~Hz}, 2 \mathrm{H}) ; 1.45(\mathrm{~s}, 18 \mathrm{H}) ;{ }^{13} \mathrm{C}$ NMR $\left(\mathrm{CDCl}_{3}, \mathrm{TMS}\right): \delta \mathrm{ppm}=153.3,133.4,130.6,129.0,128.7$, 127.4, 37.9, 33.4. Anal. Calcd for $\mathrm{C}_{20} \mathrm{H}_{24} \mathrm{O}_{2} \mathrm{~S}_{3}$ : C, 61.19; H, 6.16. Found: C, 61.25; H, 6.18.

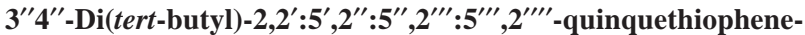
1",1"-dioxide, 20: Brown-yellow solid; mp $214^{\circ} \mathrm{C}$; MS (70 eV, EI): m/e $556\left(\mathrm{M}^{+}\right)$; IR $\left(\mathrm{SO}_{2}\right): 1284,1136 \mathrm{~cm}^{-1} ; \lambda_{\max }\left(\mathrm{CHCl}_{3}\right): 383 \mathrm{~nm}$; $36 \%$ yield. ${ }^{1} \mathrm{H}$ NMR $\left(\mathrm{CDCl}_{3}\right): \delta \mathrm{ppm}=7.34$ (doublet of doublets, $J$ $=1.2 \mathrm{~Hz}, J=5.2 \mathrm{~Hz}, 2 \mathrm{H}$ ), 7.31 (doublet of doublets, $J=1.2 \mathrm{~Hz}, J$ $=3.6 \mathrm{~Hz}, 2 \mathrm{H}), 7.29(\mathrm{~d}, J=4.0 \mathrm{~Hz}, 2 \mathrm{H}), 7.26(\mathrm{~d}, J=3.6 \mathrm{~Hz}, 2 \mathrm{H})$, 7.09 (doublet of doublets, $J=4.0 \mathrm{~Hz}, J=5.2 \mathrm{~Hz}, 2 \mathrm{H}), 1.51$ (s, $18 \mathrm{H}$ ); ${ }^{13} \mathrm{C} \mathrm{NMR}\left(\mathrm{CDCl}_{3}, \mathrm{TMS}\right): \delta \mathrm{ppm}=154.3,141.5,136.5,133.5,132.0$, 128.2, 127.7, 125.6, 124.8, 124.0, 38.4, 33.6. Anal. Calcd for $\mathrm{C}_{28} \mathrm{H}_{28} \mathrm{O}_{2}$ $\mathrm{S}_{5}$ : C, 66.22; H, 4.32. Found C, 66.07; H, 4.34.

Photoluminescence Measurements. Sample excitation was performed with an Ar ion laser with $\lambda_{\mathrm{ex}}=363 \mathrm{~nm}$. PL efficiencies were measured using a 4 in. integrative sphere (Labsphere) ${ }^{22}$ and the PL signals collected with a CCD Ocean Optics spectrograph. All measurements were carried out under dry nitrogen. Absorption and photoluminescence spectra in solution were recorded using a Perkin-Elmer $\lambda 5$ spectrophotometer and a Spex Fluorolog II spectrofluorimeter, respectively. Solutions were $10^{-5} \mathrm{M}$ in methylene chloride and Decalin (Baker Analyze, purified by silica gel chromatography). Solid-state absorption spectra were obtained with a Perkin-Elmer UV/vis/NIR $\lambda$ 900. PL efficiencies of cast films of oligomers (from chloroform) were similar to those obtained for the corresponding microcrystalline powders. The quality of the cast films obtained from the longer oligomers was better than that from the shorter ones. Good quality films were obtained in most cases by spin-coating under carefully controlled conditions (this point will be adressed in a different paper). Polymers P3 and P5 were scarcely soluble in chloroform, and PL efficiencies were only measured for the microcrystalline powders.

Electrochemical Measurements. Electrochemical experiments on Pt electrodes were performed by cyclic voltammetry (CV), using a three-electrode cell with separated compartments, with an EG\&G PAR M270A potentiostat/galvanostat. A quasi reference electrode (Ag wire) was used, and all the potential data were then calculated versus saturated calomel electrode (SCE). The Ag potential was checked versus SCE after each set of measurements. The $\mathrm{CVs}$ were performed in $\mathrm{CH}_{3} \mathrm{CN}-$ $\mathrm{Et}_{4} \mathrm{NBF}_{4}, 0.2 \mathrm{M}$-molecule $1 \cdot 10^{-3} \mathrm{M}$ at $100 \mathrm{mV} \mathrm{s}{ }^{-1}$ in a Mbraun Labmaster 130 drybox (oxygen and water contents $<1 \mathrm{ppm}$ ) at room temperature. Both $\mathrm{CH}_{3} \mathrm{CN}$ and $\mathrm{Et}_{4} \mathrm{NBF}_{4}$ were reagent grade products purified before use.

Computational Methods. Ab initio calculations were carried out at the B3LYP/6-31G* level using the Gaussian94 series of programs. ${ }^{23}$ The minima on the torsional profile were fully optimized by standard gradient techniques and checked by frequency analysis. Optimized coordinates are reported as Supporting Information. Molecular me-

(21) Nakayama, J.; Yamaoka, S.; Hoshino, M. Tetrahedron Lett. 1988 , 29,1161 .

(22) De Mello, J. C.; Wittmann, H. F.; Friend, R. H. Adv. Mater. 1997, $9,230$.

(23) Frisch, M. J.; Trucks, G. W.; Schlegel, H. B.; Gill, P. M. W.; Johnson, B. G.; Robb, M. A.; Cheeseman, J. R.; Keith, T.; Petersson, G. A.; Montgomery, J. A.; Raghavachari, K.; Al-Laham, M. A.; Zakrzewsky, V. G.; Ortiz, J. V.; Foresman, J. B.; Cioslowski, J.; Stefanov, B. B.; Nanayakkara, A.; Challacombe, M.; Peng, C. Y.; Ayala, P. Y.; Chen, W.; Wong, M. W.; Andres, J. L.; Replogle, E. S.; Gomperts, R.; Martin, R. L.; Fox, D. J.; Binkley, J. S.; Defrees, D. J.; Baker, J.; Stewart, J. P.; HeadGordon, M.; Gonzalez, C.; Pople, J. A. Gaussian 94, revision E.2; Gaussian Inc.: Pittsburgh, PA, 1995. 
chanics calculations were carried out using the MM3(96) program. ${ }^{24}$ To the missing torsional constants $V 1, V 2$, and $V 3$ for the atom types $18-2-2-42$ the values $-1,0$, and 6 were assigned respectively which allowed satisfactory reproduction of the TO ab initio profile. UV transitions were calculated by ZINDO/S $-\mathrm{CI}(6 \times 6)$ single-point calculations using HyperChem integrated package. ${ }^{25}$

Acknowledgment. We are grateful to MURST ("Electrochemical and Electronic Devices with Polymer Components")

(24) Allinger, N. L.; Q. C. P. E. Indiana University, Bloomington, IN 47405 .

(25) HyperChem, rel 5.1, from HyperCube, Waterloo, Ontario, Canada. for financial support. Thanks are due to Mr. R. Primavera, Istituto di Radioastronomia of Area Ricerca CNR, Bologna, Italy, for his help with photographic facilities.

Supporting Information Available: Tables of Cartesian coordinates and energies of TO anti, TO syn, and PO twisted (PDF). This material is available free of charge via the Internet at http://pubs.acs.org.

JA002037P 